\title{
US regional variations in rates, outcomes, and costs of spinal arthrodesis for lumbar spinal stenosis in working adults aged $40-65$ years
}

\author{
Micheal Raad, MD, Jay S. Reidler, MD, MPH, Mostafa H. El Dafrawy, MD, Raj M. Amin, MD, \\ Amit Jain, MD, Brian J. Neuman, MD, Lee H. Riley III, MD, Daniel M. Sciubba, MD, \\ Khaled M. Kebaish, MD, and Richard L. Skolasky, ScD
}

Department of Orthopaedic Surgery, The Johns Hopkins University, Baltimore, Maryland

\begin{abstract}
OBJECTIVE It is important to identify differences in the treatment of common diseases over time and across geographic regions. Several studies have reported increased use of arthrodesis to treat lumbar spinal stenosis (LSS). The purpose of this study was to investigate geographic variations in the treatment of LSS by US region.

METHODS The authors reviewed inpatient and outpatient medical claims from 2010 to 2014 using the MarketScan Commercial Claims and Encounters database (Truven Health Analytics), which includes data on commercially insured members younger than 65 years. ICD-9 code 724.02 was used to identify patients aged $\geq 40$ and $<65$ years who underwent surgery for "spinal stenosis of the lumbar region" and for whom LSS was the only principal diagnosis. The primary outcome was the performance of spinal arthrodesis as part of the procedure. Geographic regions were based on patient residence and defined according to the US Census Bureau as the Northeast, Midwest, South, and West.
\end{abstract}

RESULTS Rates of arthrodesis, as opposed to decompression alone, varied significantly by region, from $48 \%$ in the South, to $42 \%$ in the Midwest, $36 \%$ in the Northeast, and $31 \%$ in the West. After controlling for patient age, sex, and Charlson Comorbidity Index values, the differences remained significant. Compared with patients in the Northeast, those in the South $(\mathrm{OR} 1.6,95 \% \mathrm{Cl} 1.50-1.75)$ and Midwest $(\mathrm{OR} 1.3,95 \% \mathrm{Cl} 1.18-1.41)$ were significantly more likely to undergo spinal arthrodesis. On multivariate analysis, patients in the West were significantly less likely to have a prolonged hospital stay (> 3 days) than those in the Northeast (OR $0.84,95 \% \mathrm{Cl} 0.75-0.94)$. Compared with the rate in the Northeast, the rates of discharge to a skilled nursing facility were lower in the South (OR $0.41,95 \% \mathrm{Cl} 0.31-0.55)$ and West (OR $0.72,95 \% \mathrm{Cl} 0.53-0.98)$. The 30 -day readmission rate was significantly lower in the West (OR $0.81,95 \% \mathrm{Cl}$ $0.65-0.98$ ) than in the Northeast and similar between the other regions. Mean payments were significantly higher in the Midwest (mean difference $\$ 5503,95 \%$ CI \$4279-\$6762), South (mean difference \$6187, 95\% Cl \$5041-\$7332), and West (mean difference $\$ 7732,95 \% \mathrm{Cl} \$ 6384-\$ 9080$ ) than in the Northeast.

CONCLUSIONS The use of spinal arthrodesis, as well as surgical outcomes and payments for the treatment of LSS, varies significantly by US region. This highlights the importance of developing national recommendations for the treatment of LSS.

https://thejns.org/doi/abs/10.3171/2018.5.SPINE18184

KEYWORDS geographic region; lumbar spinal stenosis; spinal arthrodesis; surgical trends

$\mathrm{L}$ UMBAR spinal stenosis (LSS) is often a debilitating condition that is associated with substantial pain and disability related to degenerative bony overgrowth impinging on neural structures in the lumbar spine. The primary goal of LSS surgery is to decompress the compromised neural structures. Several studies have reported similar or superior long-term outcomes af- ter surgical decompression compared with nonoperative treatment in LSS patients who were candidates for surgery. $2,10,14,22$ However, the role of spinal arthrodesis in these patients is more controversial. Although arthrodesis is often recommended for patients with concomitant scoliosis or spondylolisthesis, ${ }^{18}$ it has not been shown to produce better outcomes than decompression alone in patients with

ABBREVIATIONS CCI = Charlson Comorbidity Index; CI = confidence interval; ICD-9 = International Classification of Diseases, Ninth Revision; LOS = length of stay; LSS = lumbar spinal stenosis; OR = odds ratio; SD = standard deviation; SNF = skilled nursing facility; USD = US dollars.

SUBMITTED February 14, 2018. ACCEPTED May 22, 2018.

INCLUDE WHEN CITING Published online November 2, 2018; DOI: 10.3171/2018.5.SPINE18184. 
isolated LSS and is therefore not recommended in this patient population..$^{5,11,12,16}$ Arthrodesis has also been shown to be associated with worse postoperative outcomes, including higher complication rates, prolonged length of stay (LOS), and greater resource use..$^{5,8,13}$ Nevertheless, recent studies have reported a dramatic increase in the number of arthrodesis procedures performed for LSS.7, $7,13,21$ This increase was particularly pronounced in the US. Recently, Lønne et al. ${ }^{9}$ showed that, for patients with isolated LSS and similar baseline characteristics, the rate of arthrodesis was $50 \%$ in Boston, Massachusetts, compared with $14 \%$ in Norway. Studies that assessed temporal trends in and outcomes after the surgical treatment of LSS reported significant variability by geographic region within the US. ${ }^{6,19,21}$ However, geographic variability was analyzed only as a covariate in these studies and not as a primary variable of interest. We believe that a thorough understanding of the geographic variability in surgical trends and outcomes is essential for establishing nationwide consensus on the optimal surgical treatment of LSS.

To our knowledge, no studies have assessed surgical trends and outcomes according to geographic region in the working US population aged 40-65 years, in whom surgery for LSS is most common. Therefore, we compared 1) rates of spinal arthrodesis, 2) outcomes, and 3) temporal trends from 2010 to 2014 in working adults surgically treated for LSS across US geographic regions.

\section{Methods}

This study does not qualify as human subjects research and thus is not subject to institutional review board approval.

\section{Patient Sample}

Our patient sample is from inpatient and outpatient medical claims for 2010 through 2014 from the MarketScan Commercial Claims and Encounters database (Truven Health Analytics), which includes data on commercially insured members younger than 65 years. Patients whose age was listed as $\geq 40$ and $<65$ years were included in this study. Patients without a continuous 12 months of coverage were excluded because some longterm outcomes, such as hospital readmission, were analyzed. The International Classification of Diseases, Ninth Revision (ICD-9) 4 code 724.02 was used to identify patients who underwent surgery with "spinal stenosis of the lumbar region" as the only principal diagnosis. Patients with concomitant diagnoses, such as scoliosis or spondylolisthesis, were excluded. The Charlson Comorbidity Index (CCI) with the Elixhauser modification, which is predictive of postoperative outcomes in orthopedic patients, was used for risk stratification..$^{15}$

\section{Geographic Regions and States}

Geographic regions were based on the location of patient residence and were defined according to the US Census Bureau as the Northeast (Connecticut, Maine, Massachusetts, New Hampshire, New Jersey, New York, Pennsylvania, Rhode Island, and Vermont), Midwest (Illinois, Indiana, Iowa, Kansas, Michigan, Minnesota, Mis- souri, Nebraska, North Dakota, Ohio, South Dakota, and Wisconsin), South (Alabama, Arkansas, Delaware, District of Columbia, Florida, Georgia, Kentucky, Louisiana, Maryland, Mississippi, North Carolina, Oklahoma, South Carolina, Tennessee, Texas, Virginia, and West Virginia), and West (Alaska, Arizona, California, Colorado, Hawaii, Idaho, Montana, Nevada, New Mexico, Oregon, Utah, Washington, and Wyoming).

\section{Surgical Procedures}

Surgical procedures were categorized as decompression alone (ICD-9 code 03.09 or 80.51) or with arthrodesis (ICD-9 code 81.06, 81.07, 81.08, 81.63, or 81.64). Arthrodesis was further classified as simple, which involves a single approach (posterior or anterior) to fuse 1 or 2 spinal levels (ICD-9 code 81.06, 81.07, 81.08, or 81.62), or complex, which involves a combined anteroposterior approach and/or fusion of more than 2 levels (any combination of the following ICD-9 codes: $81.06,81.07,81.08,81.63$, or 81.64).

\section{Use of Healthcare Resources}

The healthcare resources we analyzed were payments made to hospitals (as opposed to charges) in US dollars (USD) and the LOS after surgery, in days. LOS was analyzed as a binary outcome using the 75th percentile (3 days) as a cutoff. We adjusted for inflation rates according to the Consumer Price Index, and all payments are expressed as 2014 USD equivalents.

\section{Medical Complications and Discharge Status}

Inpatient medical complications were assessed using the following ICD-9 codes: cardiopulmonary resuscitation (code 9393 or 9960), endotracheal intubation (code 9604), cardiopulmonary arrest (code 4275 or 9971), acute myocardial infarction (code 410), respiratory failure (code 51881), pulmonary embolism (code 41511), pneumonia (code 482), stroke (code 99702), and wound infection or dehiscence (code 8622, 9981, 9983, or 9985). Patients were categorized as being discharged to home or to a skilled nursing facility (SNF).

\section{Statistical Analysis}

The 4 US regions were compared with respect to baseline patient demographic characteristics and the rates of arthrodesis and complex arthrodesis. Univariate and multivariate logistic regression models controlling for potential confounders were used to compare outcomes and the likelihood of undergoing arthrodesis and complex arthrodesis among the 4 regions. The annual likelihood of undergoing arthrodesis/complex arthrodesis for each region was estimated using logistic regression. Statistical significance was set at $p<0.05$. Statistical analyses were performed using Stata software (version 15, StataCorp, LLC).

\section{Results \\ Patient Sample}

The enrollment per year in the database was approximately 2.75 million patients in 2010, 2.76 million in 2011, 
TABLE 1. Patient and surgical characteristics by US region for 19,885 patients who underwent surgery for LSS, 2010-2014

\begin{tabular}{|c|c|c|c|c|c|}
\hline Variable & Northeast & Midwest & South & West & $\mathrm{p}$ Value \\
\hline LSS surgeries & $4004(20)$ & $5174(26)$ & $7231(36)$ & $3476(18)$ & \\
\hline Patient age in yrs, mean & $56.4 \pm 6.0$ & $56.1 \pm 6.1$ & $56.1 \pm 6.2$ & $56.4 \pm 6.0$ & 0.001 \\
\hline Female patients & $1662(42)$ & $2293(44)$ & $3336(46)$ & $1529(44)$ & $<0.001$ \\
\hline $\mathrm{CCl}$ & & & & & $<0.001$ \\
\hline 0 & $2652(66)$ & $3462(67)$ & $5045(70)$ & 2477 (71) & \\
\hline 1 & $940(24)$ & $1253(24)$ & $1584(22)$ & $717(21)$ & \\
\hline$>1$ & $412(10)$ & $459(9)$ & $602(8)$ & $282(8)$ & \\
\hline Arthrodesis & $1423(36)^{\star}$ & $2172(42)^{*}$ & $3451(48)^{*}$ & $1063(31)^{\star}$ & $<0.001$ \\
\hline Complex arthrodesis & $93(7) \dagger$ & $160(7) \dagger$ & $290(8) \dagger$ & $136(13) \dagger$ & $<0.001$ \\
\hline
\end{tabular}

Data are number of patients or cases (\%) unless otherwise indicated. Mean values are presented with SDs.

* Expressed as a percentage of all surgical procedures.

$\dagger$ Expressed as a percentage of all fusion procedures.

2.67 million in 2012, 2.12 million in 2013, and 2.20 million in 2014. The annual incidence of surgery for LSS per 1000 enrollees during that period was 1.7 in $2010,1.8$ in 2011 and 2012, 1.5 in 2013, and 1.2 in 2014. During the study period, 20,279 patients underwent surgery for LSS, of whom 394 were excluded for missing data on geographic location. We included 19,885 patients in our analysis (Table 1). The mean patient age was 56 years (standard deviation [SD] 6.1), and $44 \%$ of patients $(n=8820)$ were women. The CCI value was 0 for $69 \%$ of patients $(n=$ $13,636), 1$ for $23 \%$ of patients ( $\mathrm{n}=4494)$, and 2 or more for $9 \%$ of patients $(\mathrm{n}=1755)$.

\section{Patient Characteristics by Region}

Patient characteristics differed significantly by region. The proportion of women was highest in the South (46\%) and lowest in the Northeast (42\%). The highest proportion of patients with a CCI of 0 was in the West (71\%), and the lowest proportion was in the Northeast (66\%).

\section{Arthrodesis Rates by Region and State}

The rates of arthrodesis (simple or complex) differed significantly by region as follows: South (48\%), Midwest $(42 \%)$, Northeast (36\%), and West (31\%). The rates of complex arthrodesis also varied significantly by region as follows: West (13\%), South (8\%), and Northeast and Midwest (both 7\%) (Table 1).

The 4 states with the highest rates of arthrodesis were Delaware (70.4\%), Tennessee (59.9\%), Indiana (59.0\%), and Virginia (57.1\%). The 4 states with the lowest rates of arthrodesis were Hawaii (0.00\%), Oregon (20.8\%), North Dakota (23.1\%), and Massachusetts (23.9\%) (Table 2). Figure 1 shows a map with shading gradients representing ranges of arthrodesis rates by state.

After we controlled for patient age, sex, and CCI, the differences in arthrodesis rates among the 4 regions were significantly different. Compared with patients in the Northeast, those in the South (odds ratio [OR] 1.6, 95\% confidence interval [CI] 1.50-1.75) and Midwest (OR 1.3, 95\% CI 1.18-1.41) were significantly more likely to undergo arthrodesis, whereas patients in the West were signifi- cantly less likely to undergo arthrodesis (OR $0.79,95 \%$ CI $0.73-0.88)$. For patients who underwent arthrodesis, the likelihood of undergoing complex arthrodesis was similar in the Midwest and Northeast regions and significantly higher (both $\mathrm{p}<0.001$ ) in the South (OR 1.3,95\% CI 1.041.69) and West (OR 2.1, 95\% CI 1.61-2.81) (Fig. 2).

\section{Changes in Surgical Trends Over Time by Region}

From 2010 to 2014, the rates of arthrodesis (complex and simple) increased in all 4 US regions. The rate of complex arthrodesis among patients undergoing arthrodesis similarly increased (Fig. 3). The rates of arthrodesis increased significantly over time in all regions, as follows: Northeast ( $\mathrm{p}<0.001$; OR 1.1, 95\% CI 1.05-1.15), Midwest ( $p<0.001$; OR 1.1, 95\% CI 1.05-1.15), South ( $<<0.001$; OR 1.08, 95\% CI 1.04-1.11), and West ( $\mathrm{p}=0.001$; OR 1.1, 95\% CI 1.04-1.16). For patients who underwent arthrodesis, the likelihood of undergoing complex arthrodesis increased significantly in the Northeast (OR $1.55,95 \%$ CI 1.32-1.81), Midwest (OR 1.45, 95\% CI 1.28-1.64), South (OR 1.38, 95\% CI 1.26-1.5), and West (OR 1.44, 95\% CI $1.25-1.65)($ all $\mathrm{p}<0.001)$.

\section{Univariate Analysis of Outcomes by Region}

The rates of postoperative medical complications were similar among the 4 regions $(\mathrm{p}=0.711)$. Patients in the Northeast were most likely to have an LOS longer than 3 days $(22.2 \%, \mathrm{p}=0.003)$. Thirty-day readmission rates were highest in the Northeast $(7 \%, p=0.04)$, whereas 90 day readmission rates were highest in the South $(9.3 \%, \mathrm{p}=$ 0.004). Patients in the Northeast were most likely of those in any region to be discharged to an SNF (2.8\%), whereas those in the South were the least likely to be discharged to an SNF $(1.1 \%, \mathrm{p}<0.001)$. The mean payments to hospitals also differed significantly by region. The West had the highest payments (mean $\$ 30,549$, SD $\$ 34,740$ ), and the Northeast had the lowest (mean $\$ 22,867$, SD \$26,435) (p $<0.001$; Table 3).

\section{Multivariate Analysis of Outcomes by Region}

Patient age, sex, and CCI value were controlled for on 
TABLE 2. Rates of spinal arthrodesis for LSS by US state and the District of Columbia, 2010-2014

\begin{tabular}{|c|c|c|}
\hline Rank & State & No. $(\%)^{*}$ of Arthrodesis Procedures \\
\hline 1 & Delaware & $54(70.4)$ \\
\hline 2 & Tennessee & $396(59.9)$ \\
\hline 3 & Indiana & $654(59.0)$ \\
\hline 4 & Virginia & $450(57.1)$ \\
\hline 5 & South Carolina & $878(56.0)$ \\
\hline 6 & Rhode Island & $51(54.9)$ \\
\hline 7 & Mississippi & $144(54.9)$ \\
\hline 8 & North Carolina & $465(54.8)$ \\
\hline 9 & Kentucky & $338(54.1)$ \\
\hline 10 & Utah & $123(53.7)$ \\
\hline 11 & Nebraska & $45(53.3)$ \\
\hline 12 & Alabama & $384(52.1)$ \\
\hline 13 & Connecticut & $336(50.6)$ \\
\hline 14 & lowa & $109(50.5)$ \\
\hline 15 & Missouri & $395(48.6)$ \\
\hline 16 & Idaho & $106(48.1)$ \\
\hline 17 & Florida & $732(47.0)$ \\
\hline 18 & Louisiana & $250(46.8)$ \\
\hline 19 & Georgia & $850(46.2)$ \\
\hline 20 & Montana & $40(45.0)$ \\
\hline 21 & Vermont & $7(42.9)$ \\
\hline 22 & New York & $833(41.8)$ \\
\hline 23 & Maryland & $127(41.7)$ \\
\hline 24 & Kansas & $121(41.3)$ \\
\hline 25 & South Dakota & $17(41.2)$ \\
\hline 26 & New Jersey & $266(41.0)$ \\
\hline 27 & Colorado & $215(40.9)$ \\
\hline 28 & Ohio & $1353(40.7)$ \\
\hline 29 & Wisconsin & $239(40.6)$ \\
\hline 30 & District of Columbia & $5(40.0)$ \\
\hline 31 & Arkansas & $105(40.0)$ \\
\hline 32 & Texas & 1601 (39.7) \\
\hline 33 & Michigan & $1145(39.7)$ \\
\hline 34 & New Hampshire & $129(39.5)$ \\
\hline 35 & Maine & $46(39.1)$ \\
\hline 36 & Wyoming & 23 (39.1) \\
\hline 37 & Arizona & $197(35.0)$ \\
\hline 38 & Nevada & $244(34.8)$ \\
\hline 39 & Illinois & $917(34.0)$ \\
\hline 40 & Alaska & $18(33.3)$ \\
\hline 41 & New Mexico & $145(33.1)$ \\
\hline 42 & Pennsylvania & $2102(30.5)$ \\
\hline 43 & West Virginia & $195(29.7)$ \\
\hline 44 & California & $1744(27.0)$ \\
\hline 45 & Washington & $413(26.6)$ \\
\hline 46 & Oklahoma & $257(25.3)$ \\
\hline 47 & Minnesota & $166(24.7)$ \\
\hline 48 & Massachusetts & $234(23.9)$ \\
\hline
\end{tabular}

CONTINUED IN NEXT COLUMN »
» CONTINUED FROM PREVIOUS COLUMN

TABLE 2. Rates of spinal arthrodesis for LSS by US state and the District of Columbia, 2010-2014

\begin{tabular}{clc}
\hline Rank & \multicolumn{1}{c}{ State } & No. $(\%)^{*}$ of Arthrodesis Procedures \\
\hline 49 & North Dakota & $13(23.1)$ \\
\hline 50 & Oregon & $207(20.8)$ \\
\hline 51 & Hawaii & $1(0.00)$ \\
\hline
\end{tabular}

${ }^{*}$ Expressed as a percentage of all surgical procedures in the state for lumbar spinal stenosis.

multivariate regression analysis. LOS was similar in the Midwest, Northeast, and South. Patients in the West were significantly less likely to have a prolonged LOS compared with those in the Northeast $(\mathrm{p}=0.003$; OR 0.84$)$. The rates of postoperative medical complications were similar across all regions $(\mathrm{p}>0.05)$. The 30 -day readmission rate was significantly lower in the West $(\mathrm{p}=0.039$; OR 0.81) compared with the Northeast, and similar across the other regions. The 90-day readmission rates were similar among regions $(\mathrm{p}>0.05)$. The rates of discharge to an SNF were similar in the Northeast and Midwest. However, they were significantly lower in the South $(\mathrm{p}<$ 0.001; OR 0.41) and West $(p=0.039$; OR 0.72) compared with the Northeast. The mean payments were significantly higher in the Midwest (mean difference $\$ 5503,95 \%$ CI \$4279-\$6726), South (mean difference \$6187, 95\% CI \$5041-\$7332), and West (mean difference \$7732, 95\% CI \$6384-\$9080) compared with the Northeast (all p < 0.001; Table 4).

\section{Changes in Postoperative Outcomes Over Time by Region}

The likelihood of a prolonged LOS did not differ significantly over time in any region $(\mathrm{p}>0.05)$. The likelihood of having a postoperative medical complication was significantly higher only in the South $(p=0.02$; OR 1.19$)$. The rates of 30-day and 90-day readmission, as well as the likelihood of being discharged to an SNF, were similar over time in each region $(\mathrm{p}>0.05)$. There was a significant increase in payments to hospitals during the study period in all regions $(\mathrm{p}<0.05)$, which was highest in the Northeast (mean difference \$2664/year, p < 0.001; Table 5).

\section{Discussion}

This study describes variations in surgical trends, outcomes, and costs of surgery to treat isolated LSS in working US adults by geographic region. Even after controlling for potential confounders, there were significant variations in the rates of arthrodesis among the 4 regions, with the highest rates in the South and Midwest and the lowest rate in the West. Further analysis showed that patients who underwent arthrodesis in the West were significantly more likely to undergo a complex arthrodesis procedure compared with their counterparts in the Northeast.

A study by Alosh et al. ${ }^{1}$ reported similar results, whereby the highest rates of anterior cervical spine surgery were in the South and the lowest were in the Northeast. 


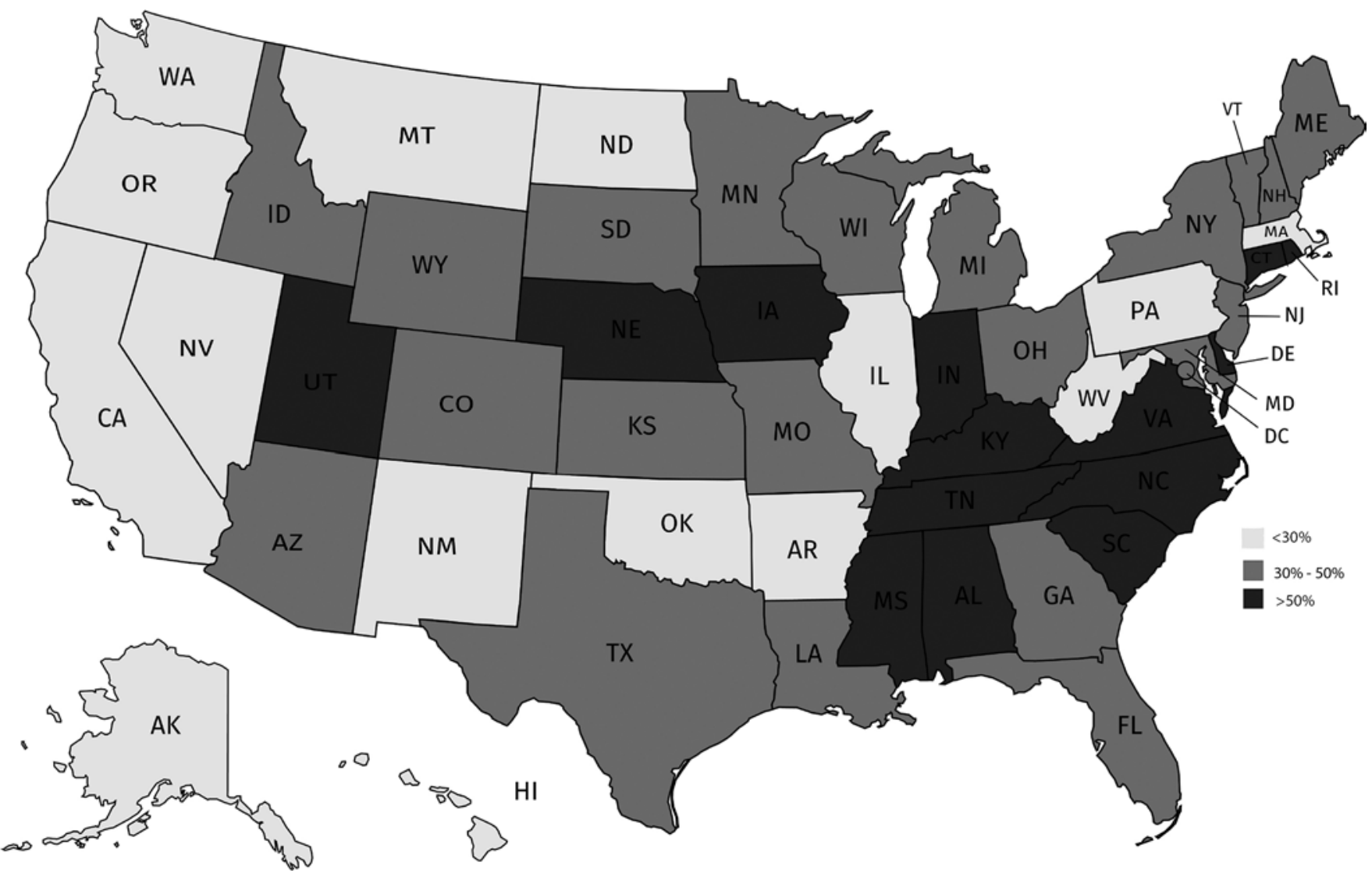

FIG. 1. Map of the US showing rates of spinal fusion surgery for isolated LSS by state.

In an attempt to explain regional variation in procedure choice for the treatment of degenerative lumbar disease in Ontario, Canada, Bederman et al. ${ }^{3}$ showed that surgeon preference was the dominant factor affecting procedure type. Similar findings were reported for patients undergoing knee replacement surgery in Ontario. ${ }^{23}$ Although sur- geon preferences may have contributed to the differences in surgical trends for the treatment of isolated LSS in our study, we believe that several potential factors, such as cultural expectations, financial reimbursement, and surgeon education, may also play a role. Given the scant research attempting to explain regional variation in surgical trends
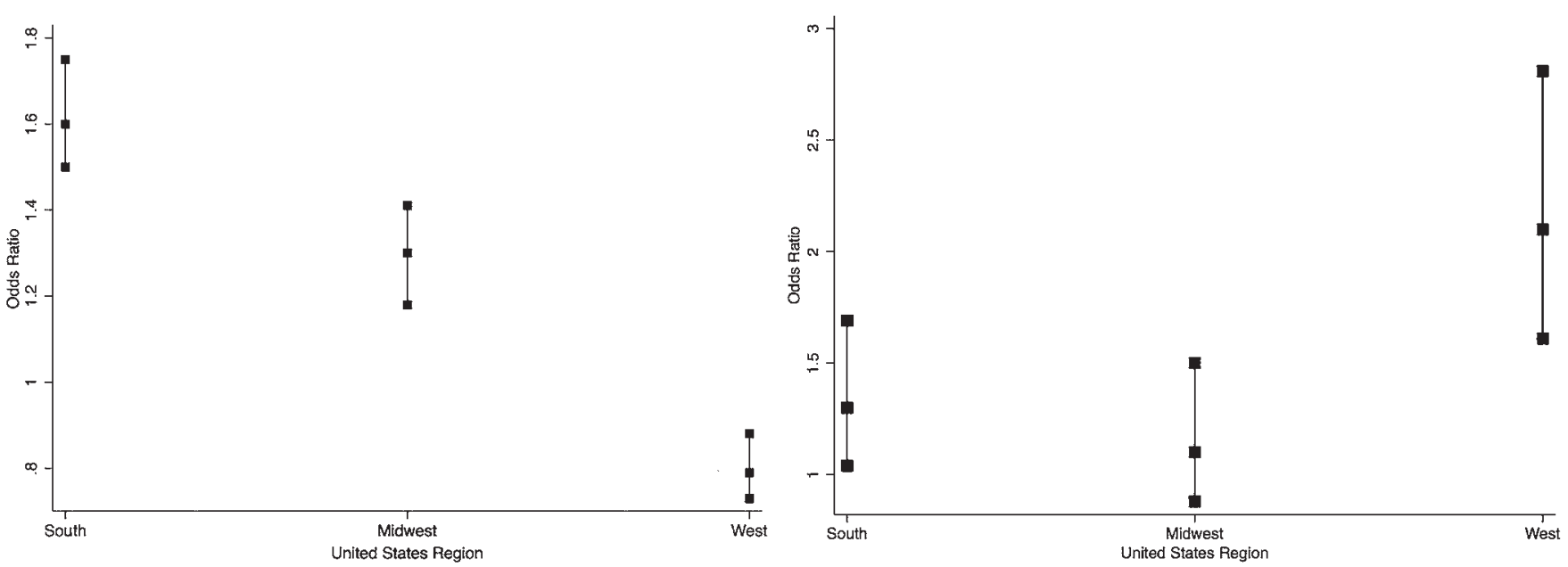

FIG. 2. Odds, by US region, of undergoing a spinal fusion procedure (as opposed to decompression alone) (left) or complex fusion procedure (as opposed to a simple fusion procedure) (right) using the Northeast region as referent. Data based on 19,855 patients with a principal diagnosis of LSS, 2010-2014. Error bars indicate 95\% confidence intervals. 

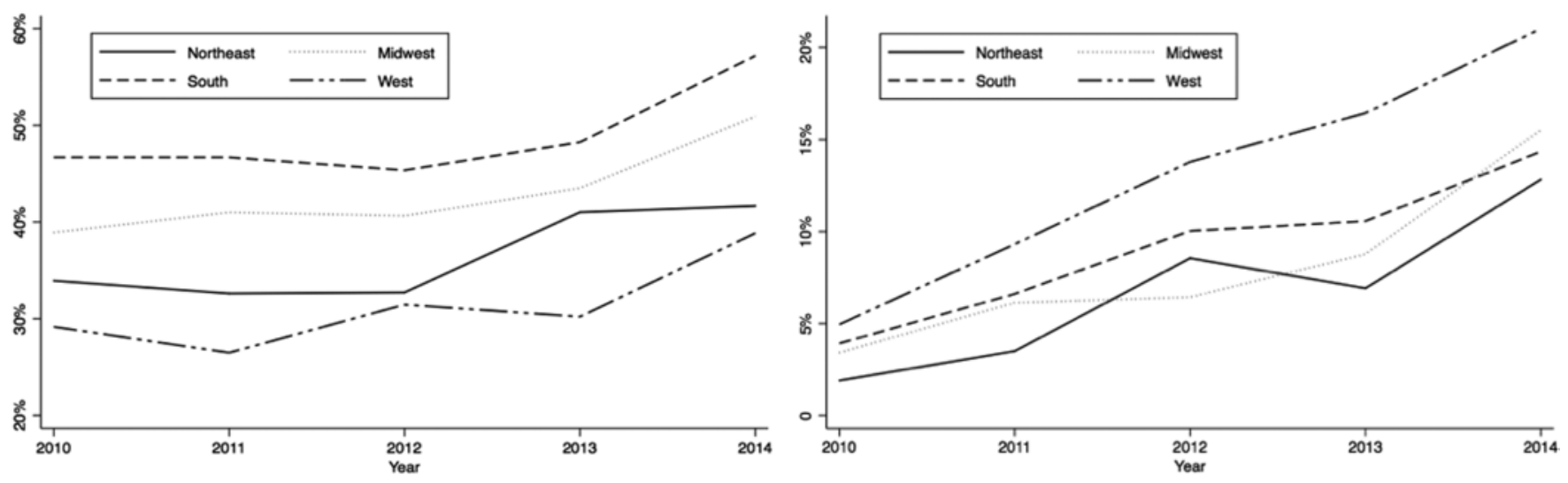

FIG. 3. Left: Rates of fusion surgery as a percentage of all LSS surgeries from 2010 to 2014 . Right: Rates of complex fusion during the same period as a percentage of all fusions by US region. Increases were statistically significant for all fusion and complex fusion rates.

in the US, there is a need to investigate this phenomenon further to understand what influences surgeon decisions by region. It is important to note, however, that there was substantial variability in fusion rates within the regions. Therefore, generalization of our findings must be made with that in mind.

Previous studies have shown an increase in rates of arthrodesis performed for various degenerative lumbar disease conditions. ${ }^{8,13}$ This study supports these results and further shows that this trend is consistent across all 4 US regions. Furthermore, we show that the rise in the rates of arthrodesis in the various regions was not accompanied by a rise in medical complications. In an attempt to explain this phenomenon, the US Department of Health and Human Services conducted a nationwide study in 2013. ${ }^{20}$ They found that the rise in arthrodesis rates (both simple and complex) from 1997 to 2012 was accompanied by a rise in the purchasing of spinal instrumentation by hospitals from physician-owned distributors. However, the study's results on the geographic variation in the use of physician-owned distributors were based on very small sample sizes (21 states had fewer than 20 patients each), and no conclusions were drawn with regard to this factor.

Although all of the outcomes we analyzed in this study varied significantly by region on univariate analysis, most did not differ after we controlled for patient age, sex, and general health status, which highlights these factors as potential confounders. On multivariate analysis, patients in the West were significantly less likely to have a prolonged LOS, to be readmitted to the hospital (at 30 or 90 days), or to be discharged to an SNF. Although the worse postoperative outcomes associated with arthrodesis compared to decompression alone ${ }^{8,13}$ may partially explain why the West had lower complication rates, such speculation about our findings in the Northeast may not be justified. Despite the relatively low rates of arthrodesis in the Northeast, the rates of discharge to an SNF and medical complications were relatively high.

Medicare reimbursement for spinal surgery procedures varies significantly by geographic region. ${ }^{17}$ Our results support this finding in private insurer payments for working US adults. Interestingly, the West had the highest payments to hospitals after adjustment for covariates, despite having the lowest rates of arthrodesis. When examining factors affecting differential reimbursement by Medicare for spinal procedures, Schoenfeld et al. ${ }^{17}$ concluded that some hospitals were inherently more "expensive," and that this was not affected by regional variation in salaries, diagnosis, procedure, demographic characteristics, or healthcare use. This inherent difference might partially explain the differences in hospital payments that we found in our study. However, other factors, such as physician salaries,

TABLE 3. Postoperative outcomes by US region for 19,885 patients who underwent surgical correction of LSS, 2010-2014

\begin{tabular}{|c|c|c|c|c|c|}
\hline Variable & Northeast & Midwest & South & West & $\mathrm{p}$ Value \\
\hline LOS $>3$ days & 887 (22.2) & $1080(20.9)$ & $1552(21.5)$ & $663(19.1)$ & 0.008 \\
\hline Medical complication & $64(1.6)$ & $81(1.6)$ & $101(1.4)$ & $47(1.4)$ & 0.711 \\
\hline 30-day readmission & $237(5.9)$ & $286(5.5)$ & $434(6.0)$ & $163(4.7)$ & 0.04 \\
\hline 90-day readmission & $388(9.7)$ & $474(9.2)$ & $745(10)$ & $284(8.2)$ & 0.004 \\
\hline Discharge to SNF & $111(2.8)$ & $110(2.1)$ & $82(1.1)$ & $68(2.0)$ & $<0.001$ \\
\hline Payments in USD* & $22,867 \pm 26,435$ & $28,459 \pm 28,511$ & $29,161 \pm 29,722$ & $30,549 \pm 34,740$ & $<0.001$ \\
\hline
\end{tabular}

Data are presented as number of patients (\%) unless otherwise indicated.

* Expressed as mean \pm SD in 2014 USD equivalents. 
TABLE 4. Adjusted odds/mean difference of postoperative outcomes by US region using the Northeast as referent after adjusting for patient age, sex, and CCl for 19,885 patients who underwent surgery for lumbar spinal stenosis, 2010-2014

\begin{tabular}{|c|c|c|c|c|c|c|}
\hline \multirow[b]{2}{*}{ Outcome } & \multicolumn{2}{|l|}{ Midwest } & \multicolumn{2}{|l|}{ South } & \multicolumn{2}{|l|}{ West } \\
\hline & $\mathrm{OR}(95 \% \mathrm{Cl})$ & $p$ Value & OR $(95 \% \mathrm{Cl})$ & p Value & OR $(95 \% \mathrm{Cl})$ & $\mathrm{p}$ Value \\
\hline LOS $>3$ days & $0.93(0.84-1.03)$ & 0.157 & $0.97(0.88-1.07)$ & 0.516 & $0.84(0.75-0.94)$ & 0.003 \\
\hline Medical complication & $1(0.72-1.40)$ & 0.963 & $0.93(0.67-1.27)$ & 0.634 & $0.9(0.62-1.32)$ & 0.6 \\
\hline 30-day readmission & $0.94(0.79-1.12)$ & 0.502 & $1.04(0.88-1.22)$ & 0.652 & $0.81(0.65-0.98)$ & 0.039 \\
\hline 90-day readmission & $0.95(0.83-1.1)$ & 0.502 & $1.1(0.97-1.25)$ & 0.151 & $0.85(0.73-1.0)$ & 0.057 \\
\hline Discharge to SNF & $0.78(0.59-1.02)$ & 0.066 & $0.41(0.31-0.55)$ & $<0.001$ & $0.72(0.53-0.98)$ & 0.039 \\
\hline Difference in mean payment, USD* & $5503(4279-6726)$ & $<0.001$ & $6187(5041-7332)$ & $<0.001$ & 7732 (6384-9080) & $<0.001$ \\
\hline
\end{tabular}

* Mean difference expressed in 2014 USD equivalents.

TABLE 5. Annual OR/mean difference in postoperative outcomes by US region for 19,885 patients who underwent surgery for LSS, 2010-2014

\begin{tabular}{|c|c|c|c|c|c|c|c|c|}
\hline \multirow[b]{2}{*}{ Outcome } & \multicolumn{2}{|l|}{ Northeast } & \multicolumn{2}{|l|}{ Midwest } & \multicolumn{2}{|l|}{ South } & \multicolumn{2}{|l|}{ West } \\
\hline & OR $(95 \% \mathrm{Cl})$ & $\begin{array}{c}p \\
\text { Value }\end{array}$ & OR $(95 \% \mathrm{Cl})$ & $\begin{array}{c}p \\
\text { Value }\end{array}$ & OR $(95 \% \mathrm{Cl})$ & $\begin{array}{c}p \\
\text { Value }\end{array}$ & OR $(95 \% \mathrm{Cl})$ & $\begin{array}{c}p \\
\text { Value }\end{array}$ \\
\hline LOS $>3$ days & $0.99(0.94-1.04)$ & 0.7 & $0.99(0.94-1.04)$ & 0.82 & $1.02(0.98-1.06)$ & 0.33 & $1(0.94-1.06)$ & 0.99 \\
\hline Medical complication & $1.07(0.89-1.27)$ & 0.48 & $1.07(0.90-1.26)$ & 0.45 & $1.19(1.03-1.37)$ & 0.02 & $1.03(0.83-1.28)$ & 0.79 \\
\hline 30-day readmission & $1.06(0.96-1.16)$ & 0.26 & $1.03(0.95-1.13)$ & 0.44 & $1.02(0.95-1.09)$ & 0.63 & $0.94(0.83-1.06)$ & 0.3 \\
\hline 90-day readmission & $0.98(0.91-1.06)$ & 0.67 & $1(0.93-1.08)$ & 0.93 & $0.98(0.93-1.04)$ & 0.48 & $0.97(0.88-1.06)$ & 0.49 \\
\hline Discharge to SNF & $1.08(0.94-1.23)$ & 0.23 & $1.05(0.91-1.21)$ & 0.5 & $1.15(0.98-1.35)$ & 0.076 & $1.15(0.96-1.38)$ & 0.13 \\
\hline $\begin{array}{l}\text { Difference in mean } \\
\text { payment, USD* }\end{array}$ & $2664(2074-3253)$ & $<0.001$ & 1641 (1046-2235) & $<0.001$ & $1090(578-1601)$ & $<0.001$ & $1518(652-2383)$ & $<0.001$ \\
\hline
\end{tabular}

${ }^{*}$ Mean difference expressed in 2014 USD equivalents.

regional variation in instrument prices, and other financial factors, could not be assessed and likely play a substantial role in this variability. Furthermore, payments to hospitals increased significantly over time in all regions, with the most pronounced increase in the Northeast and the lowest in the West. These findings were true after we controlled for patient age, which is a known determinant of hospital costs.

This study has several potential limitations. It is a large national database study, and medical billing codes were used to determine patient diagnoses. Medical billing codes do not reflect disease severity, and some surgeons might not have coded for concomitant diagnoses, such as scoliosis or spondylolisthesis. However, the use of a consistent billing code across all regions likely minimized the regional differences in disease severity. This study has a similar potential limitation in coding for procedures; however, the use of a consistent code inherently controlled for that variation as well. As with other large national database studies, risk adjustment across the 4 regions was incomplete because some relevant variables, such as body mass index, were unavailable. However, we attempted to address that problem by adjusting for known and available risk factors such as age, sex, and CCI value. Unlike the regions, some states had very small sample sizes and the results for these states might not reflect accurate arthrodesis rates. Nevertheless, we believe that our results highlight important trends in the surgical treatment of working US adults with LSS.

\section{Conclusions}

Given the large discrepancy $(31 \%-48 \%)$ in arthrodesis rates for the same diagnosis across the 4 US regions, there is a need for further investigation into the causes of this variation. A better understanding of this regional variation is important to inform attempts to create national consensus guidelines for the treatment of isolated LSS.

\section{References}

1. Alosh H, Riley LH III, Skolasky RL: Insurance status, geography, race, and ethnicity as predictors of anterior cervical spine surgery rates and in-hospital mortality: an examination of United States trends from 1992 to 2005. Spine (Phila Pa 1976) 34:1956-1962, 2009

2. Amundsen T, Weber H, Nordal HJ, Magnaes B, Abdelnoor M, Lilleâs F: Lumbar spinal stenosis: conservative or surgical management? A prospective 10-year study. Spine (Phila Pa 1976) 25:1424-1436, 2000

3. Bederman SS, Coyte PC, Kreder HJ, Mahomed NN, McIsaac WJ, Wright JG: Who's in the driver's seat? The influence of patient and physician enthusiasm on regional variation in degenerative lumbar spinal surgery: a population-based study. Spine (Phila Pa 1976) 36:481-489, 2011

4. Centers for Disease Control and Prevention: ICD-9-CM: In- 
ternational Classification of Diseases, 9th Revision, Clinical Modification. Washington, DC: Department of Health \& Human Services, 2011

5. Chang W, Yuwen P, Zhu Y, Wei N, Feng C, Zhang Y, et al: Effectiveness of decompression alone versus decompression plus fusion for lumbar spinal stenosis: a systematic review and meta-analysis. Arch Orthop Trauma Surg 137:637650,2017

6. Ciol MA, Deyo RA, Howell E, Kreif S: An assessment of surgery for spinal stenosis: time trends, geographic variations, complications, and reoperations. J Am Geriatr Soc 44:285-290, 1996

7. The Dartmouth Atlas Working Group: Variation in the Care of Surgical Conditions: Spinal Stenosis. Hanover, NH: Trustees of Dartmouth College, 2014

8. Deyo RA, Mirza SK, Martin BI, Kreuter W, Goodman DC, Jarvik JG: Trends, major medical complications, and charges associated with surgery for lumbar spinal stenosis in older adults. JAMA 303:1259-1265, 2010

9. Lønne G, Schoenfeld AJ, Cha TD, Nygaard OP, Zwart JAH, Solberg T: Variation in selection criteria and approaches to surgery for lumbar spinal stenosis among patients treated in Boston and Norway. Clin Neurol Neurosurg 156:77-82, 2017

10. Ma XL, Zhao XW, Ma JX, Li F, Wang Y, Lu B: Effectiveness of surgery versus conservative treatment for lumbar spinal stenosis: A system review and meta-analysis of randomized controlled trials. Int J Surg 44:329-338, 2017

11. Machado GC, Ferreira PH, Harris IA, Pinheiro MB, Koes BW, van Tulder M, et al: Effectiveness of surgery for lumbar spinal stenosis: a systematic review and meta-analysis. PLoS One 10:e0122800, 2015

12. Machado GC, Ferreira PH, Yoo RI, Harris IA, Pinheiro MB, Koes BW, et al: Surgical options for lumbar spinal stenosis. Cochrane Database Syst Rev 11:CD012421, 2016

13. Machado GC, Maher CG, Ferreira PH, Harris IA, Deyo RA, McKay D, et al: Trends, complications, and costs for hospital admission and surgery for lumbar spinal stenosis. Spine (Phila Pa 1976) 42:1737-1743, 2017

14. Malmivaara A, Slätis P, Heliövaara M, Sainio P, Kinnunen H, Kankare J, et al: Surgical or nonoperative treatment for lumbar spinal stenosis? A randomized controlled trial. Spine (Phila Pa 1976) 32:1-8, 2007

15. Menendez ME, Neuhaus V, van Dijk CN, Ring D: The Elixhauser comorbidity method outperforms the Charlson index in predicting inpatient death after orthopaedic surgery. Clin Orthop Relat Res 472:2878-2886, 2014

16. Resnick DK, Watters WC III, Mummaneni PV, Dailey AT, Choudhri TF, Eck JC, et al: Guideline update for the performance of fusion procedures for degenerative disease of the lumbar spine. Part 10: lumbar fusion for stenosis without spondylolisthesis. J Neurosurg Spine 21:62-66, 2014
17. Schoenfeld AJ, Harris MB, Liu H, Birkmeyer JD: Variations in Medicare payments for episodes of spine surgery. Spine $\mathbf{J}$ 14:2793-2798, 2014

18. Sengupta DK, Herkowitz HN: Lumbar spinal stenosis. Treatment strategies and indications for surgery. Orthop Clin North Am 34:281-295, 2003

19. Taylor VM, Deyo RA, Cherkin DC, Kreuter W: Low back pain hospitalization. Recent United States trends and regional variations. Spine (Phila Pa 1976) 19:1207-1213, 1994

20. United States Department of Health \& Human Services: Spinal Devices Supplied by Physician-Owned Distributors: Overview of Prevalence and Use. (https://oig.hhs.gov/oei/ reports/oei-01-11-00660.asp) [Accessed June 19, 2018]

21. Weinstein JN, Lurie JD, Olson PR, Bronner KK, Fisher ES: United States' trends and regional variations in lumbar spine surgery: 1992-2003. Spine (Phila Pa 1976) 31:2707-2714, 2006

22. Weinstein JN, Tosteson TD, Lurie JD, Tosteson ANA, Blood E, Hanscom B, et al: Surgical versus nonsurgical therapy for lumbar spinal stenosis. N Engl J Med 358:794-810, 2008

23. Wright JG, Hawker GA, Bombardier C, Croxford R, Dittus RS, Freund DA, et al: Physician enthusiasm as an explanation for area variation in the utilization of knee replacement surgery. Med Care 37:946-956, 1999

\section{Disclosures}

Dr. Neuman reports receipt of support from DePuy Synthes for non-study-related clinical or research effort. Dr. Riley reports direct stock ownership in Avitus and Spinal Kinetics. Dr. Sciubba reports a consultant relationship with Medtronic, DePuy-Synthes, Stryker, NuVasive, K2M, and Baxter. Dr. Skolasky reports a personal relationship with the North American Spine Society and Quality of Life Research.

\section{Author Contributions}

Conception and design: Skolasky, Raad, Reidler. Acquisition of data: Skolasky, Raad. Analysis and interpretation of data: Raad. Drafting the article: Raad, Reidler, El Dafrawy. Critically revising the article: Reidler, Amin, Jain, Neuman, Riley, Sciubba, Kebaish. Reviewed submitted version of manuscript: all authors. Approved the final version of the manuscript on behalf of all authors: Skolasky. Statistical analysis: Skolasky, Raad, Reidler. Administrative/technical/material support: Skolasky. Study supervision: Skolasky

\section{Correspondence}

Richard L. Skolasky: The Johns Hopkins University, Baltimore, MD.rskolas1@jhmi.edu. 